\title{
Safety and Efficacy of Lornoxicam and Diclofenac in Patients with Post Traumatic Pain- A Review
}

\author{
Mohmed Najem M. ${ }^{1}$, Mukilan D. ${ }^{2}$, Jayakumari S. ${ }^{3}$
}

${ }^{1}$ Department of Pharmacy Practice, School of Pharmaceutical Sciences, Vels Institute of Sciences, Technology and Advanced Studies (VISTAS), Chennai, Tamilnadu, India. ${ }^{2}$ Department of Pharmacy Practice, School of Pharmaceutical

Sciences, Vels Institute of Sciences, Technology and Advanced Studies (VISTAS), Chennai, Tamilnadu, India.

${ }^{3}$ Department of Pharmacognosy, School of Pharmaceutical Sciences, Vels Institute of Sciences, Technology and

Advanced Studies (VISTAS), Chennai, Tamilnadu, India.

\section{ABSTRACT}

\section{BACKGROUND}

Post-traumatic pain after a traumatic injury is common. Physical injury or injury can bring about huge harm to your tissues and bones. All things considered, experiencing ceaseless pain after a horrible physical issue isn't bizarre. In fact, it is routinely expected after absurd injuries, for instance, those bolstered in an accident. Non-steroidal anti-inflammatory drugs usually abbreviated as NSAIDs, are the drugs with analgesic, antipyretic and in higher doses, with anti-inflammatory effects. NSAIDs inhibit cyclooxygenase (COX) 1 and 2. Similar to other NSAIDs, diclofenac is associated with serious dose-dependent gastrointestinal, cardiovascular, and renal adverse effects. Diclofenac is a nonsteroidal anti-inflammatory drug (NSAID) class of the phenylacetic acid with anti-inflammatory, pain relieving, and antipyretic properties. So, the side effects are the symptoms created because of cyclooxygenase inhibitory action. Lornoxicam has been studied to be used in post-traumatic pain, Lornoxicam is a strong analgesic and, NSAID of the oxicam class with better tolerability profile when contrasted with different NSAIDs. New drug products comprising of diclofenac potassium salt were related with quicker absorption and fast onset of pain relief. It has been shown to be effective in the treatment of postoperative pain, spine surgery, post cardiac surgery, and rheumatoid arthritis (RA). However, there are just a couple of studies accessible in literature looking at post employable pain-relieving impacts of lornoxicam and diclofenac. In this manner, the current review was substantiated to validate and compare the painrelieving safety and efficacy of lornoxicam and diclofenac in intense post traumatic pain.

\section{KEY WORDS}

Post Traumatic Pain, NSAIDS, Safety, Efficacy
Corresponding Author:

Dr. Jayakumari $S$.,

Department of Pharmacognosy,

School of Pharmaceutical Sciences,

Vels Institute of Sciences, Technology \& Advanced Studies (VISTAS), Chennai, Tamilnadu, India.

E-mail: mohamednajem960@gmail.com

DOI: $10.14260 / j e m d s / 2020 / 399$

Financial or Other Competing Interests: None.

How to Cite This Article: Najem MM, Mukilan D, Jayakumari S. Safety and efficacy of lornoxicam and diclofenac in patients with post traumatic pain- a review. J. Evolution Med. Dent. Sci. 2020;9(24):1827-1833,

10.14260/jemds/2020/399

Submission 02-04-2020,

Peer Review 15-05-2020,

Acceptance 23-05-2020,

Published 15-06-2020. 


\section{BACKGROUND}

It isn't uncommon for a patient to encounter steady, extreme pain without an obvious reason after the underlying injury has recuperated. Post-traumatic pain is any agony that happens after the healing of wounds from physical injury. Following a horrendous physical issue, gentle to serious uneasiness is typical. Steps ought to be taken to treat your physical issue including setting bones, applying stitches, expelling remote items from wounds, cleaning wounds, etc as it applies to your interesting case. In the event that your inconvenience continues following a total recuperation you should search out clinical consideration, as this isn't ordinary.

As indicated by World Health Organization (WHO) injury is the main source of death among people age 15 to 44 years and will be the third driving reason for death and handicap in all ages in 2020. Road car accident (RTC) is one of the primary drivers of injury liable for roughly 50 million wounds, every year, around the world.[1-2]

Injury patients incorporate a wide range of physiologically different patient populations including solid youthful competitors, kids, and fragile older. To give ideal torment the executives care to these patients, it is important that experts are solid and steady to and current with using present day proof-based information and practices. Moreover, injury patients who present with different wounds, substance misuse, postponed care, just as mental and intense subject matters confound the consideration procedure. ${ }^{[3-4]}$

1977 lornoxicam was patented and approved for medical use in 1997. It is utilized for the treatment of different kinds of pain, inflammation, Rheumatoid Arthritis, Spondylitis, Osteoarthritis, surgery, sciatica, and other inflammation. ${ }^{[5]}$ Lornoxicam is also called as chlortenoxicam and it nonsteroidal anti-inflammatory drugs under oxicam family. Commonly used routes of lornoxicam administration are oral and parenteral structures. Not at all like other known oxicams, disposal half-life of lornoxicam is generally short (around four hours), which is profitable concerning decency. Diclofenac was administration orally or intramuscular (IM) injection in dosage from 50 to $75 \mathrm{mg}$, or for long term use up to $150 \mathrm{mg}$ per day.[6] In 1965 diclofenac was patented by Ciba-Geigy and approved for medical use in United States in 1988. Generic medication is also available for diclofenac.[5,7] Available route of administration for diclofenac is oral, intramuscular, intravenous, transdermal and rectal.[8] Diclofenac in the substance types of acid, potassium salt or sodium salt is accessible on the pharmaceutical market in an enormous number of medicinal items in different dose structures and with various routes of administration. ${ }^{[9,10]}$ They incorporate oral dosage forms like tablets and cases, generally with altered modified release, rectal dose forms, infusions, items applied or splashed on the skin, mucoadhesive dose forms and eye drops.[11] Pharmaceutical forms most ordinarily contain diclofenac as sodium salt. Lornoxicam is an NSAID which has pharmacokinetic and pharmacodynamic properties similar to those of the oftenused drug Diclofenac. Bio- availability of Diclofenac is 50$60 \%$ and bioavailability of Lornoxicam is $90 \%$. In most post traumatic pain circumstances peripheral nociceptors are enacted and typical afferences are directed by means of an intact nociceptive system.

\section{POST TRAUMATIC PAIN}

Any serious injury to the body is designated "physical injury."

\section{Two Primary Types of Physical Trauma}

- Blunt force trauma, which is the point at which an item or power hits the body with enough power to cause a blackout, profound cut, or break a bone.

- $\quad$ Penetrating trauma, which is the point at which an item punctures the skin and makes an open injury.

Some regular sorts of horrendous wounds incorporate traumatic cerebrum injury, spinal line injury, spinal breaks, awful removal, facial injury, acoustic injury, squash injury, blackout, and broken bones.

Post-traumatic pain after a traumatic physical injury is common. In most of the cases, the incessant pain is the consequence of nerve harm (causalgia or mimo-causalgia) brought about by the injury. Nerve damage is a frequent reason for a persistent pain even after recovering from the physical injury is complete. No injury is too small to even consider causing post-traumatic pain. Indeed, even a sprain can bring about post- traumatic pain. Truth be told, the nerve doesn't really need to be harmed to cause torment. Some of the time, pressure on a nerve because of the injury is adequate to cause torment that can go from gentle to serious distress. Specialists don't completely comprehend why a few wounds trigger interminable torment; in any case, it's accepted that it might be a defective correspondence between the focal and peripheral sensory systems, as well as inappropriate inflammatory response.[12]

\section{Most Common Symptoms of Post Traumatic Pain}

- A portion of the more typical indications of post-awful torment include:

- Nonstop burning or throbbing torment, mainly in an arm, hand, leg, or foot.

- Changes in skin temperature. The skin may show up sweat-soaked and afterward become cold.

- $\quad$ Changes in skin shading. The skin can seem white and mottled to red or blue.

- Changes in skin surface. The skin may get delicate and touchy to contact. It can be slender or sparkly in the area affected.

- Changes in hair and nail development.

- $\quad$ Reduced capacity to move the influenced body part.

- Joint solidness, expanding, and harm.

- Muscle fits, shortcoming, and misfortune (decay).

- Affectability to contact or cold. The region might be overly sensitive to contact or cold temperatures.

- Swelling over the painful region.

- The pain can be worsened due to emotional pressure.

For certain patients, the side effects will be reduced on their own. In others, interminable pain and brokenness can endure for quite a long time or years.[13] 


\section{Management of Traumatic Pain}

Organization of quickly acting intravenous operators in little dosages at visit interims until help with discomfort is accomplished is suggested. This permits the professional to decide the patient's basal necessities before beginning longacting prescriptions or patient-controlled absence of pain. Hypotension in light of analgesics is the most regularly demonstrative of hypovolemia and should provoke a quest for mysterious discharge while further revival happens. While the complete disposal of agony isn't for all intents and purposes achievable, multimodal torment the board methods including the organization of at least two medications with various reducing systems can give reasonable absence of pain. These medications might be directed by means of a similar course or by various courses.[14,15]

\section{PAIN ASSESSMENT SCALE}

The notable visual analogue scale (VAS) and numeric rating scale (NRS) for appraisal of torment force concur well and are similarly touchy in evaluating intense agony after medical procedure, and they are both better than a four-point verbal categorical rating scale (VRS). They work best for the patient's abstract inclination of the force of agony at this moment-present torment power. They might be utilized for most noticeably awful, least, or normal torment throughout the last $24 \mathrm{~h}$, or during the most recent week. There are a few confinements with this, as memory of agony isn't exact and frequently shaded by changing setting factors. They are additionally used to survey 'repulsiveness' of torment and to review effect of agony on work. The commonly available scales for accessing the pain are enlisted as follows visual analog scales (VAS), numerical rating scales (NRS), categorical scales, Wong-Baker faces pain scale, Flass scale, cries scale, comfort scale, McGill pain scale, colour analog scale, Mankosi pain scale, brief pain inventory and descriptor differential scale of pain intensity Visual analogue scales (VAS) are psychometric reaction scales used to gauge emotional attributes or mentalities and have been utilized in the past for a huge number of clutters, just as in statistical surveying and sociology examinations, among others. VAS was first depicted in 1921 and alluded to at the time as a "realistic rating strategy". The underlying distribution, which secured close to one page, was introduced as another technique for the executive's faculty to assess the laborers allocated to them.[16-17]

Patients were assessed at baseline (day 0) and week 2 (day 14) and week 4 (day 28). Improvement in pain intensity on the VAS at every assessment visit was viewed as the essential result. The VAS is a legitimate evaluation instrument. It brought more prominent affectability and more noteworthy measurable capacity to information assortment and investigation by permitting a more extensive scope of reactions.

It expelled inclination that was presented by analyst addressing, and it permitted realistic transient examinations. Auxiliary results were improvement in the torment force on Knee Injury and Osteoarthritis Outcome Score (KOOS) subscale, hostile to pompous impact, weight-bringing down impact, patient's worldwide appraisal for by and large indication alleviation, doctor's worldwide assessment of treatment, and against ulcer impact. The KOOS is a legitimate, solid, and responsive self-directed instrument utilized for assessing present moment and long-haul follow-up of knee injury, including $\mathrm{OA}^{\left[{ }^{[18]}\right.}$ The patients were solicited to record the number from scenes of tooting over the past $24 \mathrm{~h}$ before directing medicine and on day 7 . The anti- flatulent effect was evaluated by looking at the mean fall in number of scenes of tooting. The weight-bringing down impact was evaluated by looking at the mean fall in weight on day 28 with baseline weight. Anti-ulcer impact was surveyed by recording the quantity of $\mathrm{H}_{2}$ blocker tablets that patients devoured during the investigation time frame. The necessity of salvage prescription all through the examination time frame was recorded for a situation report structure. Consistence with study meds was checked in each visit. Adverse events (AEs) announced or saw during the investigation time frame were recorded for the situation report structure at each examination visit.[19,20]

\section{NONSTEROIDAL ANTI-INFLAMMATORY DRUGS}

NSAIDs are one of the most generally prescribed classes of medicine for pain and inflammation.[21] They are answerable for roughly $5-10 \%$ of all drugs prescribed every year.[22] The pervasiveness of NSAID use in patients more than 65 years of age is as high as $96 \%$ in the general work on setting. [23] Roughly $7.3 \%$ of older patients more than 60 years of age filled at any rate one NSAID remedy in one year time frame.[24] Not withstanding their anti-inflammatory, NSAIDs have antipyretic and pain relieving properties. These medications inhibit Cyclooxygenases (COXs) proteins, which are rate-deciding catalysts for prostaglandins and different prostanoids synthesis, for example, thromboxanes.

Contrasted and Nonselective NSAIDs that restrain both COX-1 and COX-2, COX-2 inhibitors (as known as coxibs) inhibit just COX-2 enzymes. COX-2 assumes all the more a job in prostaglandin mediated pain and irritation, while COX-1 assumes some housekeeping job in the insurance of gastric mucosa and in platelet haemostasis. While the gastrointestinal safety profiles of COX-2 inhibitors have improved, the cardio-nephrotoxic antagonistic impacts are as yet noteworthy.[25]

Most commonly used NSAIDS are aspirin, celecoxib, diclofenac, diflunisal, etodolac, ibuprofen, indomethacin, nabumetone, ketorolac, ketoprofen, oxaprozin, sulindac, salsalate and tolmetin. NSAIDs have an unmistakable mechanism of activity which makes them exceptionally effective therapeutically yet additionally purposes reactions that are especially basic after oral administration. It is assessed that around $21-25 \%$ of known cases of adverse drug reaction (ADR) are brought about by NSAIDs. The most incessant symptoms related with NSAID treatment, particularly when utilized on a drawn-out premise, are practical clutters of the gastrointestinal tract, kidneys, cardiovascular and central nervous systems. Non-steroidal anti-inflammatory drugs have been appeared to differ extensively as far as adverse drug reaction, contraindications and use limitations.[26-28] 


\section{LORNOXICAM}

Non-steroidal anti-inflammatory drugs (NSAIDs) are usually utilized for treatment of mellow to direct post-usable torment. Lornoxicam (an oxicam) is a non-steroidal pain relieving with generally fast beginning of activity than other oxicam subsidiaries. It is endorsed for use in musculoskeletal and joint agony issue, for example, osteoarthritis and rheumatoid joint pain; it is additionally utilized in the treatment of other difficult conditions including postoperative torment. Lornoxicam is accessible in definitions reasonable for oral just as parenteral organization. ${ }^{[29,30]}$

It is utilized in musculoskeletal and joint issue, for example, osteoarthritis and rheumatoid arthritis. It is additionally utilized in the treatment of conditions, for example, postoperative torment and has been shown to be as compelling as morphine. It is a yellow, amphiprotic crystalline compound with a sub-atomic load of $371.81 \mathrm{~g}$ mol-1 that exists as a zwitterion in the strong state.[31,32]

Chemical formula: $\mathrm{C}_{13} \mathrm{H}_{10} \mathrm{ClN}_{3} \mathrm{O}_{4} \mathrm{~S}_{2}$

IUPAC name: 6-chloro-4-hydroxy-2-methyl-1, 1-dioxo-N(pyridin-2-yl)-2H-1 $\lambda^{6}$-thieno $\quad[2, \quad 3-e] .[1,2] \quad$ thiazine-3carboxamide.

Lornoxicam is a nonselective NSAID of the oxicam class with pain relieving, mitigating, and antipyretic properties. Its inhibitory impacts on cyclooxygenases in fringe tissues decline prostaglandin creation and its consequences for endogenous dynorphins, b-endorphin levels additionally advance its focal pain relieving and anti-inflammatory effects. Recent examinations likewise proposed a pre-emptive role for lornoxicam. ${ }^{[33,34]}$

The medication has a short plasma disposal half-life, of roughly 4 to $6 \mathrm{~h}$. This short plasma half-life may to a limited extent be answerable for the lornoxicam's decreased occurrence of adverse effects. Along these lines, it is reasonable in the postoperative period for acute pain. It has been accounted for that Intravenous Patient Controlled Analgesia (IV PCA), with lornoxicam is as viable as opioid analgesics for postoperative pain management.[35]

\section{Pharmacokinetics Properties}

The bioavailability of lornoxicam after oral application is over $90 \%$. Greatest plasma focuses are accomplished after around two hours. Given ordinary liver and kidney work, the plasma half-life is around four hours. In old patients the leeway of lornoxicam is diminished by about $30 \%$ to $40 \%$; therefore, the half-life is to some degree longer. Indeed, even within the sight of impeded kidney and liver capacity, no significant contrasts in pharmacokinetics have been watched. By virtue of its short half-life, no amassing is probably going to happen even in instances of rehashed organization - as opposed to NSAID with a more drawn out half-life. Like different oxicams and diclofenac, lornoxicam is used by means of cytochrome P450 (CYP-2C9). Because of a hereditary polymorphism a few people may utilize gradually and, in this manner, have raised degrees of lornoxicam.[36]

\section{Pharmacodynamics Properties}

Lornoxicam is a functioning substance from the gathering of acidic enemy of pyretic analgesics. The amassing of acidic analgesics in the excited tissue is viewed as a huge part of their mitigating impact. In instances of excruciating fiery responses, the vessels in the aroused tissue are harmed and plasma proteins alongside bound pharmaceutical substances are released into the extravascular space. On account of the diminished $\mathrm{pH}$ esteem in aroused tissue, pain relieving acids are capable to move from the extracellular space and enter the cells more without any problem. This additionally clarifies why the span of activity of acidic substances is commonly longer than one would expect in thought of their plasma half-life. The kindled tissue most likely carries on like a profound compartment whose filling and exhaustion change in accordance with the plasma focuses with significant postponement. ${ }^{[40]}$

\section{Mechanism of Action}

A consummately adjusted hindrance of COX-1 and COX-2 is accomplished. COX-1 is a constitutive chemical communicated in numerous cells as a house keeping protein and gives homeostatic prostaglandins. COX-2 is an inducible protein, which is communicated at the beginning of aggravation in numerous cell types associated with fiery reactions. It varies from other oxicam mixes in its intense restraint of prostaglandin biosynthesis, a property that clarifies the especially articulated viability of the medication. Prostaglandins are associated with all periods of provocative occasions including fever, torment responses and physiological capacities like intestinal motility, vascular tone, renal capacity, gastric corrosive emission and so forth. The instigating occasions incorporate phorbol esters, cytokines and endotoxins. It may deliver the fringe pain relieving impacts by NO-cGMP pathway and the opening of $\mathrm{K}+$ channels. It likewise acts by development of nitric oxide. It has additionally demonstrated checked inhibitory movement on endotoxin instigated IL-6 development in THP 1 monocytes restraint of spinal nociceptive processing, height of plasma levels of dynorphin and $\beta$ endorphin following IV organization. In vitro tests have demonstrated that lornoxicam likewise repressed the with less movement on TNF alpha and IL-1â.[37,38]

\section{DICLOFENAC}

At present, diclofenac acid is a widely utilized as an antiinflammatory drug. This dynamic compound is successful pain reliever and effectively used in topical, regular systemic, extended- release and transdermal dosage forms. Of these, the transdermal conveyance framework has picked up much importance in the course of the most recent decade. At first acquainted with bypass the gastric symptoms of the oral and injectable structures, it has developed as a patientaccommodating option in contrast to the last mentioned. It can defeat the pharmacokinetic obstructions of oral and parenteral courses by bypassing the hepatic first-pass 
digestion, keeping up a consistent state plasma focus over a drawn-out time and limiting between and intra patient in constancy. Its decreased dose recurrence contrasted with the oral course, non-obtrusiveness, simplicity of organization and end likewise brings about better patient consistence. Additionally, patients are delivered from the unnecessary pain and fear related with injectable structures. At present, diclofenac acid is a broadly used as a anti-inflammatory drug. This dynamic compound is fruitful torment reliever and successfully utilized in topical, customary fundamental, expanded discharge and transdermal dose structures.

Chemical formula: $\mathrm{C}_{14} \mathrm{H}_{11} \mathrm{Cl}_{2} \mathrm{NO}_{2}$

IUPAC name: 2-[2-(2, 6-dichloroanilino) phenyl] acetic acid

Diclofenac (cyclooxygenase 1 and cyclooxygenase 2 inhibitor) is being used conventionally for many years for postoperative pain relief. It is known to accumulate in inflamed tissue where its concentration is maintained much higher than in plasma for many hours. It also has active metabolites that act as analgesic. However, there are only a few studies available in literature comparing post-operative analgesic effects of lornoxicam and diclofenac. Therefore, the present study was substantiated to evaluate the analgesic efficacy and safety of lornoxicam and diclofenac in acute postoperative pain after spinal surgery.

Diclofenac (cyclooxygenase 1 and cyclooxygenase 2 inhibitor) is being utilized conventionally for a long time as postoperative pain reliever. It is known to aggregate in aroused tissue where its fixation is kept up a lot higher than in plasma for a long time. It additionally has dynamic metabolites that go about as analgesic.[39]

\section{Pharmacodynamic Properties}

Diclofenac is a NSAID displaying pain relieving, calming, and antipyretic movement. Its method of activity isn't very much described. Despite the fact that diclofenac is delegated as a non- specific COX inhibitor, it is a particular COX-2 isoform inhibitor which adequately hinders prostaglandin-E2 and thromboxane-A2 synthesis and possesses pro-nociceptive activity at peripheral and spinal destinations.[39,40] Also, diclofenac goes about as an eicosanoid oxidoreductase inhibitor and hinders eicosanoids and lipoxins. It additionally builds plasma-endorphin levels and constricts N-methyl-Daspartate (NMDA)- intervened nociceptive release through the L-arginine-nitric oxide-cGMP (cyclic guanosine monophosphate) pathway.[41,42] Diclofenac has been appeared to lessen prostaglandin and interleukin-6 levels in plasma and synovial liquid in patients with rheumatoid joint pain and osteoarthritis. Contrasted and different NSAIDs, regardless of COX-specificity, diclofenac shows more noteworthy hindrance of platelet aggregation and goes about as a serious opponent of thromboxane-prostanoid receptor, meaning potential cardiovascular wellbeing. ${ }^{[43,44]}$

\section{Pharmacokinetic Properties}

Diclofenac is very much assimilated orally and has a determined clear volume of distribution of $0.12-0.17 \mathrm{~L} / \mathrm{kg}$.
The AUC of diclofenac is relative to the orally controlled portion in the range of 25 and $150 \mathrm{mg}$. Peak concentration in synovial liquid, which is the site of activity of NSAIDs, is accomplished 2-4 $\mathrm{h}$ in the wake of achieving top plasma levels. Diclofenac ties widely to plasma proteins (99.7\%), primarily egg whites.[45]

Following oral organization, biotransformation of diclofenac is guaranteed mostly by single and different hydroxylation, methoxylation, and halfway glucuronidation, bringing about phenolic metabolites which are then changed over to glucuronide conjugates. Complete systemic clearance of diclofenac is $263.56 \mathrm{~mL} / \mathrm{min}$. After glucuronidation and sulfation, the metabolites of diclofenac are discharged in the urine (65\%) and bile (35\%). Disposal from synovial liquid takes around 3-6 $\mathrm{h}$. The terminal half-life in plasma is $1-2$ hrs. [46]

\section{COMPARISON OF LORNOXICAM AND DICLOFENAC}

Daglar et al. (2005) examined the comparison of the impacts of lornoxicam versus diclofenac in torment the executives after heart medical procedure in a solitary blind randomized study. The investigation included 40 adult patients who were haphazardly allotted to administered diclofenac $75 \mathrm{mg}$ intramuscular 12 hourly for 48 hours or lornoxicam $8 \mathrm{mg}$ intramuscularly 8 hourly. No significant group discomfort scores were found at any point in the two groups.[47]

Sener et al (2008) in a planned, randomized, placebo controlled double blind study analysed the adequacy of lornoxicam with diclofenac, ketoprofen and dipyrone for alleviation of intense postoperative pain in tolerant experiencing septoplasty. They utilized lornoxicam $8 \mathrm{mg}$ twice every day and diclofenac $75 \mathrm{mg}$ twice every day. There was no noteworthy contrast among the remaining lornoxicam what's more, diclofenac groups. ${ }^{[48]}$

Kidd et al. (1996) compared about the efficacy and tolerability of lornoxicam and diclofenac in the treatment of patients with osteoarthritis more than 12 weeks and surveyed the viability and bearableness of lornoxicam over a follow-up time of 40 weeks. Consequences of their investigation indicated that Lornoxicam $4 \mathrm{mg}$ TID and 8 bid $\mathrm{mg}$ offer were as powerful as diclofenac $50 \mathrm{mg}$ TID for the treatment of osteoarthritis. There was no huge contrast in bearableness of these regimens.[49]

Herrmann \& Geertsen (2009) contrasted efficacy and tolerability of lornoxicam with placebo and diclofenac detailed in 164 intense sciatica/lumbo-sciatica patients utilizing randomized twofold blinded multicentre study. They detailed that lornoxicam and diclofenac had comparable painrelieving impact. Occurrence and severity of adverse effects were practically identical. By and large pass-ableness was evaluated awesome by $93 \%$ of patients. [50]

Varsha G Et al (2013) studied on the analgesic efficacy and tolerability of lornoxicam and diclofenac sodium were correlation in post usable spinal medical procedure patients. This single blinded, randomized, imminent near investigation of lornoxicam (8 $\mathrm{mg}$ ) versus diclofenac $(75 \mathrm{mg}$ ) was directed 
at 47 patients were selected the investigation. After spinal medical procedure, 23 patients got diclofenac sodium and 24 patients got lornoxicam. Pain were surveyed at pattern $(0$ min), 15 mins, 30 mins, 45 mins, 60 mins, 90 mins, 120 mins, 180 mins, 240 mins, 300 mins, and 360 mins by visual analog scale of 10 points. Adverse events were recorded for the both groups. Lornoxicam has marginally more noteworthy adequacy than diclofenac in acute post-operative pain with comparable tolerability and safety. Subsequently, it was reasoned that lornoxicam is a superior option for diclofenac in acute post-operative after spinal surgery. ${ }^{[51]}$

\section{CONCLUSIONS}

Pain as characterized by the International Association for the Study of Pain, is a terrible tactile and emotional experience related with genuine or potential tissue harm or depicted as such as damage. Early and compelling alleviation from torment in post-operative period is of significance so as to improve persistent solace and also to re-establish patient's day by day work. Selection of analgesics in the post-operative period should be guided by a person's needs. Treatment of suffering in patients after procedure on head and neck with a non-opiate pain-relieving drug permits close checking of the patient's neurologic status and NSAIDs are favoured in these circumstances. Lornoxicam was found to be absorbed faster with rapid onset of pain relief when compared to diclofenac with minimum side effects and thus be safely used as a shortterm analgesic for relieving post traumatic pain.

\section{ACKNOWLEDGEMENT}

The authors are very thankful to Vels Institute of Science Technology and Advanced Studies (VISTAS) and its management for providing research facilities and encouragement and also to the patients, who participated in this study.

\section{REFERENCES}

[1] Murray CJ, Lopez AD. Global mortality, disability, and the contribution of risk factors: global burden of disease study. Lancet 1997;349(9063):1436-42.

[2] Peden M, Scurfield R, Sleet D, et al. World report on road traffic injury prevention. Geneva: World Health Organization 2004.

[3] Cohen SP, Christo PJ, Moroz L. Pain management in trauma patients. Am J Phys Med Rehabil 2004;83(2):142-61.

[4] Gausche-Hill M, Brown KM, Oliver ZJ, et al. An evidencebased guideline for prehospital analgesia in trauma. Prehosp Emerg Care 2014;18 Suppl 1:25-34.

[5] Fischer J, Ganellin CR. Analogue-based drug discovery. Wiley-VCH 2010.

[6] Das SK, Banerjee M, Mondal S, et al. A comparative study of efficacy and safety of lornoxicam versus tramadol as analgesics after surgery on head and neck. Indian J Otolaryngol Head Neck Surg 2013;65(Suppl 1):126-30.

[7] Kasonde L, Tordrup D, Naheed A, et al. Evaluating medicine prices, availability and affordability in Bangladesh using World Health Organisation and Health Action International methodology. BMC Health Serv Res 2019;19(1):383.

[8] Sen I, Mitra S, Gombar KK. Fatal anaphylactic reaction to oral diclofenac sodium. Can J Anaesth 2001;48(4):421.

[9] Joshi S, Rapoport AM. Diclofenac potassium for oral solution (CAMBIA ${ }^{\circledR}$ ) in the acute management of a migraine attack: clinical evidence and practical experience. Ther Adv Neurol Dis 2017;10(4):217-26.

[10] Ali H, Shoaib MH, Zafar F, et al. Pharmacokinetic and bioequivalence studies of immediate release diclofenac potassium tablets $(50 \mathrm{mg})$ in healthy volunteers. Pak J Pharm Sci 2016;29(5):1671-9.

[11] Amin L, Jesmeen T, Sutradhar KB, et al. Development and in vitro evaluation of diclofenac sodium loaded mucoadhesive microsphere with natural gum for sustained delivery. Curr Drug Deliv 2013;10(6):765-70.

[12] Doupe J, Cullen CH, Chance GQ. Post-traumatic pain and the causalgic syndrome. J Neurol Psychiatry 1944;7(12):33-48.

[13] Jain SV, Bhamidipati CM, Cooney RN. Trauma transfers to a rural level 1 center: a retrospective cohort study. J Trauma Manag Outcomes 2016;10:1.

[14] Funke F. Vergleich Visueller Analogskalenmit Kategorialskalen in Offlineund Online-Design. Magisterarbeitim Studiengang Soziologie am Institutfür Soziologie des Fachbereichs Sozial- und Kulturwissenschaften der Justus-Liebig Universität Gießen 2004.

[15] Hayes MHS, Patterson DG. Experimental development of the graphics rating method. Physiol Bull 1921;18:98-99.

[16] Sener M, Yilmazer C, Yilmaz I, et al. Efficacy of lornoxicam for acute postoperative pain relief after septoplasty: a comparison with diclofenac, ketoprofen, and dipyrone. J Clin Anesth 2008;20(2):103-8.

[17] Frizziero L, Focherini MC, Valentini M, et al. Long term study on the efficacy and safety of lornoxicam in rheumatoid arthritis. Minerva Med 2002;93(4):315-20.

[18] Ahmed MO, Al-Badr AA. Lornoxicam. Chap- 6. In: Brittain HG, ed. Profiles of drug substances, excipients and related methodology. Vol. 36. Elsevier Inc 2011:205-39.

[19] Flandry F, Hunt JP, Terry GC, et al. Analysis of subjective knee complaints using visual analog scales. Am J Sports Med 1991;19(2):112-8.

[20] Roos EM, Lohmander LS. The Knee injury and osteoarthritis outcome score (KOOS): from joint injury to osteoarthritis. Health Qual Life Outcomes 2003;1:64.

[21] Abdulla A, Adams N, Bone M, et al. Guidance on the management of pain in older people. Age and Ageing 2013;42 Suppl 1:i1-57.

[22] Onder G, Pellicciotti F, Gambassi G, et al. NSAID-related psychiatric adverse events: who Is at risk? Drugs 2004;64(23):2619-27.

[23] Pilotto A, Franceschi M, Leandro G, et al. NSAID and aspirin use by the elderly in general practice: effect on 
gastrointestinal symptoms and therapies. Drugs Aging 2003;20(9):701-10.

[24] Vandraas KF, Spigset O, Mahic M, et al. Non-steroidal anti-inflammatory drugs: use and co-treatment with potentially interacting medications in the elderly. Eur J Clin Pharmacol 2010;66(8):823-9.

[25] Harirforoosh S, Asghar W, Jamali F. Adverse effects of nonsteroidal antiinflammatory drugs: an update of gastrointestinal, cardiovascular and renal complications. J Pharm Pharm Sci 2013;16(5):821-47.

[26] Kowalski ML, Makowska JS, Blanca M, et al. Hypersensitivity to nonsteroidal anti-inflammatory drugs (NSAIDs) - classification, diagnosis and management: review of the EAACI/ENDA\# and GA2LEN/HANNA. Allergy 2011;66(7):818-29.

[27] Lisowska B, Rell-Bakalarska M, Rutkowska-Sak L. Niesteroidowe leki przeciwzapalne-blaski i cienie. Reumatologia 2006;44(2):106-11.

[28] Mukilan D, Praveen D, Chowdary PR, et al. Drug-induced Parkinsonism: a review. Drug Invent Today 2018;10(2):212-5.

[29] Suresh K, Nangia A. Lornoxicam salts: crystal structures, conformations, and solubility. Cryst Growth Des 2014;14(6):2945-53.

[30] Skjodt NM, Davies NM. Clinical pharmacokinetics of lornoxicam. A short half-life oxicam. Clinical Pharmacokinet 1998;34(6):421-8.

[31] Ravic M, Salas-Herrera I, Johnston A, et al. A pharmacokinetic interaction between cimetidine or ranitidine and lornoxicam. Postgrad Med J 1993;69(817):865-6.

[32] Waldvogel HH. Antinozizeptiva. In: Analgetika antinozizeptiva adjuvanzien. Springer, Berlin, Heidelberg 2001:543-75.

[33] Hitzenberger G, Radhofer-Welte S, Takacs F, et al. Pharmacokinetics of lornoxicam in man. Postgrad Med J 1990;66 Suppl 4:S22-7.

[34] Rosenow DE, Albrechtsen M, Stolke D. A comparison of patient-controlled analgesia with lornoxicam versus morphine in patients undergoing lumbar disk surgery. Anesth Analg 1998;86(5):1045-50.

[35] Zhao H, Ye TH, Gong ZY, et al. Application of lornoxicam to patient-controlled analgesia in patients undergoing abdominal surgeries. Chin Med Sci J 2005;20(1):59-62.

[36] Berg J, Christoph T, Widerna M, et al. Isoenzyme-specific cyclooxygenase inhibitors: a whole cell assay system using the human erythroleukemic cell line HEL and the human monocytic cell line mono mac 6. J Pharmacol Toxicol Methods 1997;37(4):179-86.

[37] Berg J, Christoph T, Fellier H, et al. The Analgesic NSAID lornoxicam inhibits cyclooxygenase (COX)-1/-2, inducible nitric oxide synthase (iNOS), and the formation of interleukin (IL)-6 in Vitro. Inflamm Res 1999;48(7):369-79.
[38] Hiller A, Silvanto M, Savolainen S, et al. Propacetamol and diclofenac alone and in combination for analgesia after elective tonsillectomy. Acta Anaesthesiol Scand 2004;48(9):1185-9.

[39] Jhunjhunwala HR, Naik AK. New dimension in pain management: diclofenac-colestyramine. Indian Journal of Clinical Practice 2012;22(12):23-7.

[40] Ku EC, Lee W, Kothari HV, et al. Effect of diclofenac sodium on the arachidonic acid cascade. Am J Med 1986;80(4):18-23.

[41] Gan TJ. Diclofenac: an update on its mechanism of action and safety profile. Curr Med Res Opin 2010;26(7):171531.

[42] Dong XD, Svensson P, Cairns BE. The analgesic action of topical diclofenac may be mediated through peripheral NMDA receptor antagonism. Pain 2009;147(1-3):36-45.

[43] Gonzalez E, De la Cruz C, De Nicolas R, et al. Long-term effect of nonsteroidal anti-inflammatory drugs on the production of cytokines and other inflammatory mediators by blood cells of patients with osteoarthritis. Agents Actions 1994;41(3-4):171-8.

[44] Selg E, Buccellati C, Andersson M, et al. Antagonism of thromboxane receptors by diclofenac and lumiracoxib. Br J Pharmacol 2008;153(8):1763.

[45] Todd PA, Sorkin EM. Diclofenac sodium. A reappraisal of its pharmacodynamic and pharmacokinetic properties, and therapeutic efficacy. Drugs 1988;35(3):244-85.

[46] Gil Z, Smith DB, Marouani N, et al. Treatment of pain after head and neck surgeries: control of acute pain after head and neck oncological surgeries. Otolaryngol Head Neck Surg 2006;135(2):182-8.

[47] Daglar B, Kocoglu H, Celkan MA, et al. Comparison of the effects of lornoxicam versus diclofenac in pain management after cardiac surgery: a single-blind, randomized, active-controlled study. Curr Therap Res 2005;66(2):107-16.

[48] Kidd B, Frenzel W. A multicenter, randomized, double blind study comparing lornoxicam with diclofenac in osteoarthritis. J Rheumatol 1996;23(9):1605-11.

[49] Sener M, Yilmazer C, Yilmaz I, et al. Efficacy of lornoxicam for acute postoperative pain relief after septoplasty: a comparison with diclofenac, ketoprofen, and dipyrone. J Clin Anesth 2008;20(2):103-8.

[50] Herrmann WA, Geertsen MS. Efficacy and safety of lornoxicam compared with placebo and diclofenac in acute sciatica/lumbo-sciatica: an analysis from a randomised, double-blind, multicentre, parallel-group study. Int J Clin Pract 2009;63(11):1613-21.

[51] Varsha GJ, Nimesh PA, Dave BR, et al. A comparison of the efficacy and tolerability of lornoxicam and diclofenac sodium in patients with acute postoperative pain after spinal surgery. Am J Phytomed Clin Therap 2013;1(5):507-15. 